\section{Procrastination and the Extended Will}

\section{Joseph Heath and Joel Anderson}

To be published in Chrisoula Andreou and Mark White (eds.), The Thief of Time: Philosophical Essays on Procrastination (New York: Oxford University Press).

Abstract: In this paper, we develop an externalist understanding of procrastination and in particular, of our how our distributed will and its supportive social scaffolding enables us to keep procrastination in check (to the extent that we are able to). Thinking about procrastination in this way has several attractive implications. It provides an explanation learning about the limits of human cognition and rationality. It provides a framework for thinking creatively about new kludges and scaffolding that can improve individuals' wellbeing, without needing to rely on unrealistic and illiberal therapeutic strategies that involve changing individuals' personality or cognitive style. And, finally, it opens up a set of important and neglected issues within public policy, social ethics, and political philosophy, having to do with the collective responsibility for maintaining public (and perhaps even unchosen) forms of scaffolding.

Less than a decade ago, "rational choice theory" seemed oddly impervious to criticism. Hundreds of books, articles and studies were published every year, attacking the theory from every angle, yet it continued to attract new converts. How times have changed! The "anomalies" that Richard Thaler once blithely cataloged for the Journal of Economic Perspectives are now widely regarded, not as curious deviations from the norm, but as falsifying counterexamples to the entire project of neoclassical economics. The work of experimental game theorists has perhaps been the most influential in showing that people do not maximize expected utility, in any plausible sense of the terms "maximize," "expected," or "utility." The evidence is so overwhelming and incontrovertible that, by the time one gets to the end of a book like Dan Ariely's Predictably Irrational, ${ }^{1}$ it begins to feel like piling on. The suggestion is pretty clear: not only are people not as rational as decision and game theorists have traditionally taken them to be, they are not even as rational as they themselves take themselves to be.

This conclusion, however, is not self-evident. The standard interpretation of these findings is that people are irrational: their estimation of probabilities is vulnerable to framing effects, their treatment of (equivalent) losses and gains is asymmetric, their choices violate the sure-thing principle, they discount the future hyperbolically, and so on. Indeed, after surveying the experimental findings, one begins to wonder how people manage to get on in their daily lives at all, given the seriousness and ubiquity of these deliberative pathologies. And yet, most people do manage to get on, in some form or another. This in itself suggests an
Procrastination and the Extended Will (Heath and Anderson).doc alternative interpretation of the findings. What experimental game theorists may have demonstrated is not that people are systematically irrational, but that human rationality is heavily scaffolded. Remove the scaffolding, and we don't do very well. People are able to get on because they "offload" an enormous amount of practical reasoning onto their environment. As a result, when they are put in novel or unfamiliar environments, they perform very poorly even on apparently simple tasks.

This observation is supported by recent empirically informed shifts in philosophy of mind toward a view of cognition as (to cite the current slogan) "embodied, embedded, enactive, extended." Andy Clark, for example, has argued that "advanced cognition depends crucially on our ability to dissipate reasoning: to diffuse achieved knowledge and practical wisdom through complex social structures, and to reduce the loads on individual brains by locating those brains in complex webs of linguistic, social, political and institutional constraints." ${ }^{2}$ Clark and others have made a very plausible case for the idea that a proper assessment of human cognitive competence must include environmental components. To limit our attention to what lies within the skin-skull boundary is, in effect, to miss the big story on human rationality. Insofar as we are rational, it is often because of our ingenuity at developing "work-arounds" to the glitches in the fast-and-frugal heuristic problem-solving capabilities that natural selection has equipped us with. ${ }^{3}$ And these work-arounds often involve a detour through the environment (so-called "offloading" of cognitive burdens). This is an instance of the now widely accepted view that the evolutionary success of humans is the result not merely of adaptations in our biological endowment but also - and perhaps more significantly - in our linguistic, social, and material culture.

When it comes to practical rationality, things are no different. Yet in many discussions of the "the will," there is still a tendency to put too much emphasis on what goes on inside the agent's head. For example, the self-controlled person is usually seen as one who has a capacity to exercise tremendous willpower, not as one who is able to organize his life in such a way that he is never called upon to exercise tremendous willpower. This internalis and mentalist bias is liable to make the various "glitches" in the structure of the will - such as the temporary preference reversals induced by hyperbolic discounting - seem much more threatening to the coherence of the agent's plans than they actually are. For example, everyone procrastinates on occasion. Yet only $15-20 \%$ of adults describe themselves as

${ }^{2}$ Andy Clark, Being There: Putting Brain, Body, and World Together Again, p. 180. See also, for example, 
ability to achieve major life goals. ${ }^{4}$ This is actually lower than one might expect, simply from looking at the psychological literature on discounting.

Our objective in this paper is to articulate this conception of "the extended will" more clearly, using the strategies that people employ to overcome procrastination for the central set of examples. Procrastination, in our view, constitutes a particular type of self-control problem, one that is particularly amenable to philosophical reflection, not only because of the high volume of psychological research on the subject, but also because of the large quantity of "self-help" literature in circulation - a literature which provides an invaluable perspective on the everyday strategies that people use in order to defeat (or better yet, circumvent) this type of self-defeating behavior pattern. In general, what we find is that the internalist bias that permeates discussions of the will gives rise to a set of practical recommendations that overemphasize changing the way that one thinks about a task, while ignoring the much richer set of strategies that are available in the realm of environmental scaffolding. In the concluding section, we highlight some of the policy implications of this, particularly regarding social trends involving the dismantling of support structures.

\section{From Extended Mind to Extended Will}

To begin with a familiar example, most of us can do multiplication "in our heads" with numbers up to 10 , but cannot go beyond that - this despite the fact that we have all mastered a procedure (so-called "long multiplication") that transforms the larger problem into a set of smaller problems, each of which we are capable of solving in our head (e.g., to multiply 43 by 87 , first you multiply 7 by 3 , then you multiply 7 by 4 , etc.) Each of these subproblems we can easily solve in our heads, but the reason we can't solve the problem as a whole is that the solution to these four subproblems must be kept in working memory in order to resolve the final subproblem, which involves addition of the four products. Most of us are simply not able to remember four multiple-digit numbers like this, in order to perform a final operation on them.

Hence the most common form of "offloading" we perform is to transfer segments of our working memory onto the environment. We write things down. Obviously, the ability to encode things symbolically for this purpose constitutes the major mechanism through which language (and a number-writing system) enhances our innate cognitive abilities. Indeed,

${ }^{4}$ Piers Steel, "The Nature of Procrastination," 65.
Procrastination and the Extended Will (Heath and Anderson).doc when trying to characterize human beings as computational systems, the difference between "person" and "person with pencil and paper" is vast. It is only when we are embedded in our familiar system of artifacts that we can do even moderately sophisticated arithmetic.

In this respect the "offloading" metaphor is slightly misleading. When we "dump" the contents of our working memory onto the environment (e.g. by writing things down) we are not just doing so for purposes of storage. We park them in a form in which we are still capable of performing computations upon them. Thus features of the environment in which this information is embodied become an active component of our cognitive system. Of course, once we become properly habituated to using an external system, it may become internalized, so that we can perform the relevant transformation inside our head, much in the way that children learn first to speak out loud and only later become capable of thinking things through silently, in their heads. ${ }^{5}$ For example, older Chinese merchants who have been trained in the use of an abacus are often able to do extensive computations without the benefit of the device - although you can often see them moving their fingers slightly. Having used the abacus for so long, they are able to picture it clearly in their mind and feel the position of the beads with their fingers so well that they no longer need the actual piece of equipment. The movement of the fingers is the vestigial trace of the external origins of the cognitive competence. The scaffolding is not so much removed as absorbed.

The abacus actually provides a wealth of examples of ways that external artifacts can be used to provide "work-arounds" or "kluges," that help us to circumvent limitations of what lies within the skin-skull boundary. First there are the beads. As physical objects, these have the attractive property of staying put. Thus, when arranged into a configuration that represents a number, they can overcome limitations in our working memory (the central problem being that so little stays put there). The second major feature is that it allows the operator to replace the set of primitive arithmetic computations with a set of finger movements. Thus adding and subtracting become like positioning one's fingers on the frets of a guitar in order to produce a note - something that quickly becomes second nature, and so can be accomplished with little or no attention. Finally, the "uprights" or bars are used to represent orders of magnitude, making it possible to perform operations like "carrying the one" in a very simple, tactile way. This provides an easy way to deal with the rather unintuitive character of the notation that we use for numbers, viz. the "base" numbering

${ }^{5}$ Lev S. Vygotsky, Thought and Language - Revised Edition; See also Jerome Bruner, Acts of Meaning: Four Lectures on Mind and Culture; and James Wertsch, Mind as Action. 
Procrastination and the Extended Will (Heath and Anderson).doc system. (Think of the way that a bank teller, counting out a large sum in $\$ 20$ bills, will count out five bills, then make a stack, count out five more bills, then make a second stack, and so on.)

In each case, what the inventor of the device has done is take a cognitive operation that we find very demanding and, through clever colonization and manipulation of objects in the environment, replace it with one that we find relatively easy (or that can become quite easy through habituation). In particular, cognitive operations that must be performed consciously are mapped on to a set of physical motions that can, with practice, be performed without paying attention. Computational outcomes that must be represented linguistically are mapped on to configurations of objects that can be visualized. All of this amplifies our cognitive abilities. But it also means that, when thinking about these abilities, it is importan not to focus too narrowly on what happens in our brains. The central lesson of the literature on the "extended mind" is that we should not think of these external artifacts are merely aids to cognition, they are often a proper part of the cognitive system. They are, in this respect, more like prosthetics than tools. And, as has often been remarked in the case of the blind person's cane - the tip of which is actually the terminus of the person's sense of touch many prostheses are so well integrated into how one makes one's way through the world, that we can say we "use" them only in the sense that we can say that we "use" our fingers to type. In fact, we simply type. Similarly, we simply "add the numbers," whether it is in our heads or on paper.

\section{The Case of Procrastination}

When it comes to tasks like arithmetic, the limitations of our cognitive system are so obvious and solved in such familiar ways that no one dwells on the remarkable fact that most of us are unable to remember a set of four double-digit numbers for long enough to carry out long multiplication. Our dependence upon environmental prosthetics is self-evident. When it comes to practical rationality, on the other hand, many theorists have either ignored or denied the presence of any systematic defects. Rational choice theorists have been front and center in this campaign. Gary Becker's analysis of addiction as a consequence of straightforward, unproblematic utility-maximization represents perhaps the apogee of this tendency. ${ }^{6}$ Partly this is due to the noncognitive (or subjectivist) conception of preference that typically informs rational choice theories, which results in practical rationality being held to a lower

${ }^{6}$ Gary Becker and Kevin M. Murphy, "A Theory of Rational Addiction."
Procrastination and the Extended Will (Heath and Anderson).doc standard than theoretical rationality. After all, if one puts no constraints at all on the content of preferences, then it becomes possible to construe any action as rational (in a rather undemanding sense of the term) simply by positing a preference for doing it. ${ }^{7}$

Yet even if one says nothing at all about the content of preferences, there are still defects in our practical reasoning that can be specified at a purely formal level. The most obvious examples involve self-control problems - where individuals, upon due reflection, formulate an intention to perform some action, fail to perform it when the time comes, and subsequently regret this failure. What makes this type of situation noteworthy and problematic is the subsequent regret. It is not merely that the agent fails to follow through on the intention - this could be described simply as a change of mind. It is the fact that the agent subsequently regrets the failure that suggests that she maintains a constant preference, in some sense, for the initially intended action throughout.

An example of this is the everyday phenomenon of procrastination. A quick definition of procrastination would be to say that it occurs when:

1. an agent delays initiation of an action that is associated with some level of disutility, even though

2. the agent knows now that doing so will increase the level of disutility at the time that the act must ultimately be performed, and

3. the agent has reason to believe that she will subsequently regret having delayed the action.

This definition is intended to capture the sense in which the procrastinating agent chooses the larger-later evil over the smaller-sooner evil (procrastination is thus the converse of intemperance, in which the agent chooses the smaller-sooner good over the larger-later good). The qualifications are there in order to exclude a couple of cases in which the agent delays initiation of an aversive task, but where this is not genuine procrastination. First, it is not procrastination to put something off when something else comes up that one considers genuinely more important, and which must be attended to first. In that case, the agent has no reason to regret, ex post, the choice that he made. Second, even when one has nothing more urgent to do, merely delaying a task is not procrastination, unless things can be expected get worse somehow as a result of the delay. Sometimes we put things off just because we don't feel like doing it now, and from a certain rigorist standpoint, this might be thought to be a

${ }^{7}$ Joseph Heath, Following the Rules. 
Procrastination and the Extended Will (Heath and Anderson).doc failing of some sort. But if the delay has no significant repercussions, it is hard to see how it merits the label of procrastination, since it lacks the quality of perverseness that has made procrastination seem mysterious to so many people. Finally, it should be noted that it is the reasonable expectation of future regret that is the important element of procrastination. Whether the agent actually regrets the task later does not matter (e.g. sometimes unpleasant tasks actually do just go away, when they are deferred for long enough, even though we have no reasonable expectation that they will)

A simple example of procrastination would be leaving the dishes to stack up in the sink, even though it is easier to clean them right away, before the muck on them hardens. The behavior induces regret because, when the individual finally does settle down and perform the task, he will be aware that it is now more unpleasant or difficult than it would have been had he done it right away. A more serious example would be someone who puts off having a colonoscopy and therefore may miss having colon cancer diagnosed at an early stage. In this case, the colonoscopy does not become any more unpleasant as a result of the delay, but the individual's anticipated health outcome becomes worse (and thus the delay "makes things worse").

If "utility" is defined in terms of payoffs - with respect to how much satisfaction or dissatisfaction a sequence of events ultimately generates for the individual - procrastination foreseeably fails to maximize the individual's achieved utility level (i.e. as seen from an ex post perspective). It is because the delay in some sense makes things worse that the agent can expect to subsequently regret the delay, and therefore can be said to suffer a failure of selfcontrol. However, one of most noteworthy features of procrastination is that the agent does not suffer from any loss of intentional control throughout this period. Thus the individual who fails to do the dishes promptly is nevertheless choosing not to do the dishes at the time at which he forgoes the opportunity to do them. He is not the same as someone who gets drunk, or angry, or into some other state in which executive function is impaired, and does something that he subsequently regrets. People often procrastinate under that description (i.e. if you ask them what they haven't done something yet, they'll say "I'm procrastinating.") This is one of the reasons why a hyperbolic discounting model provides the most perspicuous representation of the phenomenon. It offers a rationalizing account of procrastination, yet one that is still able to account for the preference reversal and regret that characterizes such failures of self-control.

The hyperbolic discounting model has two central components. The first claim is that
Procrastination and the Extended Will (Heath and Anderson).doc agents not only have preferences with respect to various events that can occur, they also have a time-preference, which (all things being equal) leads them to experience delay as aversive, when it intervenes between the present and a positively valued event, and as attractive, when it intervenes between the present and a negatively valued event. ${ }^{8}$ The common way of expressing this is to say that individuals discount future satisfaction. The second component is the claim that there is a "warp" in this aversion toward delay, such that agents find a delay of a given length less aversive, the further removed it is from the present, above and beyond what can be attributed to the mere fact that the experience of this delay is delayed. ${ }^{9}$ This is typically expressed by saying that individuals discount future satisfaction in a way that is highly exaggerated in the near term - hence "hyperbolic" discounting.

The most important feature of hyperbolic discounting is that it leads individuals to rank near-term and long-term events very differently. Hyperbolic discounters have a preference ordering over distant events that is almost exactly the same as the atemporal ranking that could be derived from the "payoff" value of these events, but their ranking of more proximate events frequently deviates quite significantly from a strictly payoff-based ranking. As a result, the passage of time can lead individuals to change their preference ordering, in such a way as to make "smaller-sooner" payoffs more attractive than "largerlater" ones. This subsequently induces regret, at the time at which the "larger-later" reward could have been obtained. ("If only I had waited," the agent will say.) When the payoffs are negative, the same phenomenon occurs in reverse. Long before the dishes are dirty, the agent may see that it makes sense to wash them right away, thereby minimizing the negative payoff. Yet she waits, only to regret the decision later, once the disutility of the payoff has grown. ("If only I had done this sooner," she will say.)

There are two things that should be noted about this in passing. First, hyperbolic discounting is introduced here as a model that can be used to represent the dynamics of procrastination, not as an explanation for why individuals procrastinate. Indeed, there are a variety of theories that seek to explain the psychological underpinnings of hyperbolic discounting, in particular, why there is the "warp" in our attitude toward delay. For our purposes, it does not matter why there is a warp, only that there is this warp.

${ }^{8}$ The most important exception is "dread," which occurs when the delay of an aversive event is also

experienced aversively. This can lead people to want to "get it over with" sooner rather than later - a phenomenon that is capable of generating the opposite of procrastination. Consider a patient who opts to have a painful dental procedure done right away, by a less experienced practitioner, rather than later, by a 
Procrastination and the Extended Will (Heath and Anderson).doc

The second thing to notice about the hyperbolic discounting model is that it provides an account of procrastination and other forms of giving in to temptation without invoking what philosophers call "strict akrasia," or intentional counterpreferential choice. ${ }^{10}$ Although there is a whiff of irrationality about the dynamic inconsistency in the agent's preferences, the fact remains that, at the time at which she acts, she is acting in accordance with her occurent subjective preferences - not contrary to them. Formally speaking, there is no logical inconsistency in changing one's preferences over time, or in changing them back. Indeed, there are occasions on which we might quite easily sympathize with the agent's

"intemperate" self, the one who wants to change the decision, even knowing that he will subsequently regret having done so. ${ }^{11}$ Given how wide open our eyes typically are about what we are doing when we procrastinate, it seems unlikely that the most effective strategies for reducing procrastination will focus on simply understanding how counterproductive it is Rather, we are likely to be helped most by kluges, work-arounds, and scaffolding. ${ }^{12}$

\section{Self-Control Strategies}

In some cases, avoiding procrastination is a matter of just buckling down and doing it, a straightforward exercise of willpower. An agent who opts for such a strategy simply resolves to perform a certain action and holds steadfastly to that intention, resisting whatever inclinations may arise to revise his or her plans (along the lines of a "New Year's resolution.") We often describe people who are able to do this as having a lot of "selfdiscipline." There is no doubting that individual willpower, whatever it turns out to be, is a good thing to have in the struggle to avoid making unpleasant tasks worse by delaying them. The more complex and individualized societies become, the more individuals will need selfdiscipline if they are not to suffer disadvantages in both competitive and non-competitive contexts.

But there are reasons to doubt that "simply buckling down" will be enough to solve

$$
\begin{aligned}
& { }^{10} \text { Alfred Mele, Irrationality: An Essay on Akrasia, Self-Deception and Self-Control. } \\
& { }^{11} \text { Consider Jay Chirstensen-Szalanski's, "Discount Functions and the Measurement of Patients' Values: } \\
& \text { Women's Decisions during Childbirth," a study of the behavior of women who had chosen, prior to labor, to } \\
& \text { rofrain from using any pain control. He found that a majority reversed this decision after active labor pains } \\
& \text { had begun. He also found, however, that almost all of those who reversed their position drifted back to their } \\
& \text { original view - that pain control was undesirable - within three months postpartum. Thus their "standing" } \\
& \text { preference was for childsirth without pain control. It was only when they were actually experiencing the } \\
& \text { pain that they were fully appreciated the merits of pain control. In this case, one might easily identify with } \\
& \text { the preference at the moment of decision, and suspect that there is an element of self-deception in the } \\
& \text { "standing" preference. }
\end{aligned}
$$

${ }^{12}$ For a related discussion, see Heath, Following the Rules, 228-234.
Procrastination and the Extended Will (Heath and Anderson).doc many pathologies of the will - or, indeed, that it ever has been enough. To begin with, there are many unanswered empirical questions about how such self-discipline is possible and what the limits of it are. Several recent studies suggest that although willpower is like a muscle, and can be trained, it can also become exhausted. In experimental studies, Roy Baumeister and colleagues have shown that (human) subjects who resisted a temptation for a period of time were less able than control group members to resist a temptation that followed closely thereafter. ${ }^{13}$ If the demands of individuals for processing decisions and resisting various temptations is on the rise in increasingly complex societies, these individual capacities might easily become overtaxed - if pure willpower were all that people could rely on. It is, however, unclear to what extent the average person actually relies on individual selfdiscipline to avoid or to limit procrastination. Our suspicion is that its role is greatly exaggerated. Much of the time, what looks like sheer willpower is the result of more-or-less well-orchestrated attempts by individuals to arrange their lives in such a way as to economize on willpower, by avoiding situations that call for its exercise. We refer to this as distributed willpower, since it involves individuals creating more than one locus of self-control. ${ }^{14}$

Self-control strategies can usefully be thought of under four general categories, as part of a progression that involves movement away from the purely psychological toward the environmental.

Direct psychological strategies

There are many effective strategies that involve shifts in one's cognitive approach to an aversive task. These are ways of re-conceptualizing or re-framing tasks so as to inhibit negative tendencies, or more often, to help individuals tap into motivational resources that would be otherwise uninvolved. The system of "mental accounts" that many people use to control household spending (e.g. distinguishing "retirement savings" from "rent money" and "spending money," for instance) is a well-known example of this. ${ }^{15}$ These sorts of psychological techniques differ from "pure willpower" in that the individual is not simply forcing herself to do something, but is somehow modifying the construal of the task in such a way as to decrease the level of "forcing" that is required. We refer to such techniques as

${ }^{13}$ Mark Muraven and Roy Baumeister, "Self-Regulation and Depletion of Limited Resources: Does SelfControl Resemble a Muscle?"

${ }^{14}$ The parallel here is with "distributed cognition" within cognitive science discussions. See for example Edwin Hutchins, Cognition in the Wild. See also, Don Ross, David Spurrett, Harold Kincaid, and G. Lynn

${ }^{15}$ Richard H. Thaler, "Mental accounting and consumer choice"; Richard H. Thaler, "Saving, fungibility and
Ritions. ( 
strategic reframing.

A general approach to the analysis of such strategies can be found in "Temporal Motivation Theory" (which is, essentially, an approach to procrastination derived from the hyperbolic discounting model).${ }^{16}$ This model identifies three items as central to the dynamic of preference change, and hence procrastination: expected utility, delay, and sensitivity to delay. Thus one way in which individuals can avoid their own tendency to procrastinate is to manipulate one (or more) of these three variables.

To begin with, take the (dis)utility associated with boredom. People are most likely to procrastinate before performing boring tasks (and people who are easily bored are more likely to procrastinate). ${ }^{17}$ The natural explanation is that boredom increases the aversiveness of a task (thus diminishing expected utility). One way to avoid procrastination is therefore to try to find something interesting about the task, or to embed it within some larger construct that makes it more appealing (e.g. turning it into a game, or timing one's performance and then trying to beat that time). One might think of this as the Mary Poppins strategy: "For every job that must be done, there is an element of fun. Find the fun and, snap, the job's a game." In some cases, a mere redescription of a task can be effective in enhancing motivation, since preferences over actions have been shown to be sensitive to the language in which the action (or associated outcome) is described. ${ }^{18}$

Similarly, to overcome the tendency to put off initiating a task with a distant pay-off, one can set a sequence of intermediate goals. This strategic re-framing involves the tried-andtrue time-management strategy of breaking down an intimidating task into its component parts, each of which is much more doable. By shifting one's focus from the ultimate goal to specific intermediate steps, one not only turns an intimidating mountain into a series of doable molehills, one also reduces the delay between effort and reward (whether that reward be an intermediate treat or simply the confidence-building sense of accomplishment). So, while the reward of having written a book may be so far off as to have little motivational pull, the satisfaction associated with having written a chapter, or better yet, having met one's target of three pages per day, is likely to be much more effective. Empirical support for this reframing strategy is found in research on "implementation intentions" by Gollwitzer and colleagues. In one study, it was shown that "difficult goal intentions were completed about 3

${ }^{16}$ Steel, "The Nature of Procrastination.",

${ }^{18}$ Yaacov Trope and Nira Libennan, "Temporal Construal and Time-Dependent Changes in Preference." Procrastination and the Extended Will (Heath and Anderson).doc
times more often when participants had furnished them with implementation intentions."19 For related reasons, techniques involving visualizing the steps to be taken tends to create the impression that the results are even more proximate.

Self-management strategies

The reframing techniques described above are still relatively direct, in the sense that, when successful, they actually fix the problem, eliminating the underlying tendency to procrastinate. A person who persuades himself that cleaning up the dishes is fun is no longer tempted to procrastinate, because he no longer finds the task aversive. He may have engaged in all sorts of artful self-manipulation in order to convince himself that it is fun, yet the end result is an actual elimination of the inclination to procrastinate.

Apart from these direct strategies, there are also an enormous number of psychological "kluges" that people employ. Rather than trying to resolve or eliminate the underlying problem, here the individual simply tries to work around it. In many cases, this involves taking some other defect in our nature and using it to counteract the defect that leads us into temporary preference reversals. For example, a major limitation of the re-framing strategies just discussed is that they require quite a bit of active purposefulness, such as maintaining conscious attention, and this is often precisely what individuals are lacking in cases of procrastination. As a result, individuals may find it useful to develop automatic processes that are set up in advance and can channel their behavior in cases where their attention lapses. The classic example of this is good habits. In a sense, if you have good habits, you don't need willpower.

Closely related to this is the strategy of "psychological bundling" of tasks. The idea here is to take something that you don't particularly like doing and to combine it with something that you do like. "Singing while you work" is perhaps the best example of this, although unfortunately it's a technique that only works well with manual labor. Another example would be keeping track of how much money you're making, as you perform some employment-related task. (This is particularly effective when working on piece rates.) Once the two activities become habitually conjoined, then the psychological bundling may diminish the aversiveness of the package. And since a daily routine can itself become a source of gratification, building the performance of certain chores into a routine can amoun

${ }^{19}$ Peter M. Gollwitzer and Veronika Brandstätter, "Implementation intentions and effective goal pursuit." (Se also the chapter by Frank Wieber and Peter Gollwitzer in this volume.) 
to a form of psychological bundling.

A related strategy involves recruiting strong preferences from another domain to motivate self-control in a problematic domain. Many self-reward schemes exploit the fact that we are usually capable of different levels of self-control in different areas of life. A person who is rather miserly, for instance, may find it easy to refrain from spending money. He might therefore coax himself into performing an unpleasant task by promising to buy himself something he has long wanted, once the task is complete. In this case, the willpower he is able to exercise in one domain is "leveraged," through the self-reward strategy, into selfcontrol in another. ${ }^{20}$

Another example of self-management is what is known as "structured procrastination. ${ }^{21}$ The basic idea here is to use one's own capacity for self-deception as a way of combating procrastination. Most people, when they procrastinate, do not chose simply to sit idle. A person who is putting off doing the dishes, for instance, typically will not just stare at the wall, but will do something else, like watch television. John Perry has observed, however, that many people, rather than performing the highly aversive task that is being avoided, will perform some other mildly aversive, perhaps even marginally useful, task. Thus a person who hates a particular household chore may put it off by doing some other chore, one that is somewhat less useful, but at the same time less unpleasant (e.g. light dusting). ${ }^{22}$ Thus a person who has trouble washing the dishes might persuade himself that he really ought to clean the oven as well, and then put off doing this by washing the dishes.

Environmental strategies

Many of the examples given so far involve a certain degree of cleverness and manipulation on the part of the individual. In part, this is a reflection of the relative poverty of the psychological resources that are available to us, when it comes to dealing with selfcontrol problems. When we turn to environmental strategies, by contrast, the field of possibilities opens up considerably. Indeed, the use of environmental manipulation by individuals as a technique for enhancing self-control is absolutely routine and ubiquitous indeed, it is so commonplace that we are often in danger of overlooking it completely. (In the

${ }^{20}$ See Andreou's chapter in this volume. See also Ainslie, Breakdown of Will.

${ }_{22}^{21}$ John Perry, "Structured Procrastination."

In many cases this is undoubtedly connected to the fact that the temporary preference reversal associated with procrastination is rationalized; see Lennart Sjoberg and Tommy Johnson, "Trying to Give Up Smoking: A unpleasant, as opposed to straightforwardly pleasurable; see Perry "Structured Procrastination""
Procrastination and the Extended Will (Heath and Anderson).doc same way, when it comes to overcoming weaknesses in our memory, the mnemonist's bag of tricks seems quite exotic and recherché, when compared to the simple expedient of writing things down.)

Looking inside someone's office, their kitchen pantry, their bedroom, or even on their computer 'desktop', what one sees is an entire structure of cognitive and volitional scaffolding, a system that this person uses in order to accomplish (with varying degrees of success) routine tasks. Many aspects of the way this environment is organized are intended to facilitate self-control. People who are good at environmental manipulation try to organize their affairs in such a way as to make certain activities easier and others harder. We can distinguish three general types of environmental kluges: triggers, chutes, and ladders. Each of these represent features of the environment that either assist or discourage one from initiating and persevering with an intended task. They may have emerged by more or less adaptive happenstance, or they may have been intentionally designed, whether by the individual or someone else.

"Triggers" are environmental cues that, when appropriately placed, set automatic processes in motion (or bring them to a stop). Suppose you intend to go running every morning first thing, but once you've poured yourself a cup of coffee and opened up the morning paper, the idea of a run seems like an unpleasant interruption. Putting your running shoes in front of the coffee maker can trigger the intended routine of going for a run, before other routines kick in. Triggers can also work in tandem with other strategies, for example, by periodically reminding one of various promised rewards, thereby activating those motivational resources. In addition, triggers can function as warnings, alerting one to impending temptations or calling for a quick check of whether one is on track (such as nagscreens that pop up every time one switches to one's browser). ${ }^{23}$

Many environmental features help with task completion by making certain desirable courses of action particularly smooth and effortless. These "chutes" are setups that make it easier to slide into doing something. To take a variation on the early-morning run case: by laying out, the evening before, everything one needs, the threshold to "just doing it" is lowered. You step out of bed, the chute takes over, and the next thing you know you are running out the door. Another example comes from the literal design of one's environment. The architect Gerrit Rietveld's premier 1924 "Schröder Huis" includes, next to the entrance, a

See, for example, Merlin Mann's “Right now, what are you doing?" nag-screen at
http://www.43folders.com/2008/09/01/what-are-you-doing. 
Procrastination and the Extended Will (Heath and Anderson).doc fold-down chair and desk with storage for stationary, pens, envelopes, and postage, so that Frau Schröder could answer mail immediately upon opening it, without even leaving the entryway.

Just as chutes lower the threshold to doing the right thing, "ladders" can be positioned to raise the threshold to undertaking wasteful actions, especially when it comes to procrastination. By structuring one's environment effectively, one can reduce the distractions and temptations behind much procrastination. Again, it is often sufficient just to introduce a delay in the initiation of the time-waster. If email, instant-messaging, Solitaire, or websurfing are sources of procrastination, then simply removing bookmarks and other shortcuts or regularly shutting down the programs may provide enough of a threshold to keep one from "just checking" too often. A more extreme option is to install a product called "Software Time Lock," which allows the user to "set blocks of time during which you cannot access the Web, set blocks of time during which specific programs cannot be used, set blocks of time during which you cannot use the computer at all, set limits on how long you can access the Web each day," and so forth. ${ }^{24}$

Given that distractibility and impulsiveness are strongly correlated with procrastination, this sort of environmental management is crucially important. Even something as simple as closing the office door or working in an environment without an internet connection, telephone, cell phone reception, or what have you, can dramatically improve task performance.

\section{Social strategies}

Finally, the most obvious way to exercise self-control in the event of an anticipated failure of willpower is simply to preauthorize some other person either to act on your behalf or to impose control upon you. The locus classicus for this strategy is Ulysses's ordering his sailors to tie him to the mast and then to ignore his subsequent instructions. There are, however, a multitude of far more subtle strategies that we use, in order to offload (or perhaps one should say outsource) one's self-control onto other people.

When it comes to procrastination, the most obvious example of this is the socia institution of deadlines. By accepting a deadline, the individual essentially makes a commitment to another person that a particular task will be accomplished by a certain time. It is often not the case that this deadline coincides with any objective requirement, i.e. nothing

${ }^{24}$ See http://leithauserresearch.com/software time_lock.htm
Procrastination and the Extended Will (Heath and Anderson).doc bad actually happens if the deadline is missed, other than that the deadline is missed. And yet deadlines are often motivationally quite effective, even when everyone is aware of their artificiality. A closely related strategy is the time-honored techniques of overcommitment. If Parkinson's Law is correct ("work expands to fill the time available for its completion"), then the best way to ensure that one is working at a reasonably high intensity level is to take on too much. This makes it easier to meet deadlines, in part because it deprives one of certain rationalizations that are often used to excuse procrastination. "I'll get to it tomorrow" becomes far less persuasive, if the workload is such that there is literally no slack in the schedule (so that leaving it until tomorrow is as good as not doing it at all).

Teamwork is another closely related strategy. Like deadlines, working on a task jointly with other people brings a variety of social motives (such as the individual's normconformative disposition, desire to avoid disapproval, unwillingness to "let down the side," concern over social status) into alignment with his or her instrumental work objectives. Many people find that they can only bring themselves to exercise by playing team sports. In the same way, many people work far more effectively in groups. Many of the direct psychological strategies outlined above are also far more effective, and much easier to implement, when carried out in a social context. "Making a game of it" can require considerable imagination, when carried out in solitude. But in a social context, it is always possible to make a game out of any task, often quite literally. The most obvious way is by introducing a competitive structure into the group relations, for example, by giving a prize to the person who performs best (think of the way companies give out bonuses, or even "employee of the week" awards). In a social context, it is possible to change the incentives governing a particular task in a way that is often not possible at a purely individual level. Relatively feeble "self-rewards" can be replaced by actual rewards.

People in long-term intimate relationships often develop a very advanced division of labor between themselves. This extends to both cognitive tasks, such as remembering names, but also to practical, volitional ones. One can often see a division of self-control tasks in the way that household labor is divided up (e.g. the person least likely to buy junk food is the one who does the grocery shopping, the one who is most likely to pay the bills on time is the one who looks after the finances, etc.) More informally, couples may employ the "license to nag," whereby they essentially authorize one another to complain, criticize and even punish them for failures of willpower. They may also begin to rely upon the other person's complaints as a cue for initiating action. 
Procrastination and the Extended Will (Heath and Anderson).doc

Perhaps the most subtle mechanism of self-control is selective association. Imitation and conformity provide very powerful motives. In particular, we rely upon imitation to establish what Ap Dijksterhuis and John Bargh refer to as "default social behavior." ${ }^{25}$ Thus one way to avoid self-control failures of a particular sort is to avoid the company of those who suffer from such failures. Being around prompt, hardworking, high-achievers is one of the best ways of becoming prompt and hardworking as well. Associating with slackers is a good way of becoming a slacker.

Even from this quick survey of the available set of strategies, it is evident that they become richer and more numerous as one proceeds down the list. There is not all that much we can do, using our "onboard" resources, when it comes to controlling procrastination. When one moves into the domain of the environment, on the other hand, especially the social environment, the set of available strategies becomes less restricted. The latter seems to be limited primarily by human imagination, not any inherent limitations of the medium.

The importance of these environmental strategies can be seen in the phenomenon of "college procrastination" - the fact that college students, particularly during first and second year, experience much higher levels of "problem procrastination" than the general public. What is particularly interesting about this phenomenon is that it has little predictive significance, when it comes to determining work habits in other contexts. ${ }^{26}$ From an internalist perspective this is perhaps mysterious, but when seen from the perspective of environmental scaffolding it is entirely unsurprising. College students are given a fairly high degree of autonomy, when it comes to determining a plan of work for themselves, yet they are deprived of all the scaffolding that they have used, in the past, to offload motivational resources. Often they are living away from home for the first time, and so are missing whatever "system" they had developed for the timely completion of tasks. For example, merely studying in the same location has been shown to decrease procrastination among college students. ${ }^{27}$ This is a habit that many high-school students would have, but which ${ }^{25}$ Ap Dijksterhuis and John A. Bargh, "The Perceptual-Behavior Expressway: Automatic Effects of Social
Perception and Social Behavior." See also John A. Bargh and Tanya L. Chartrand, "The Unbearable

${ }^{26}$ Simon M. Moon and Alf

Growth Curve Analysis of J. Illingworth, "Exploring the Dynamic Nature of Procrastionation: A Latent college students and procrastination, see Mera M. Kachgal, L. Sunny Hansen, and Kevin J. Nutter, "Academic Procrastination Prevention/Intervention: Strategies and Recommendations;", Timothy A. Pychyl, Richard W. Morin, and Brian R. Salmon,"Procrastination and the Planning Fallacy: An Examination of the Study Habits of University Students;" Laura J. Solomon and Esther D. Rothblum, "Academic

Herld A. Jr. Ziest, Ted L. Rosenthal and Glenn M. White "B
Procrastination and the Extended Will (Heath and Anderson).doc could easily be lost in the transition to college. Furthermore, they are no longer under direct parental supervision, and so are cut free from what has typically been their most important social self-control mechanism.

\section{Moving Beyond Mentalistic, Individualistic, and Voluntaristic Assumptions about}

\section{Rational Action}

One could view the foregoing discussion of "externalist" strategies simply as elements in a diverse toolbox for reducing procrastination. But we believe that coming to appreciate the prevalence of distributed willpower has wider implications for our understanding of rational human agency. On what one can call the "standard model," what is needed to avoid irrationality is largely understood in mentalistic, individualistic, and voluntaristic terms. Being rational, on this view, is a matter of correct thinking, engaged in by individuals, along with the ability to exert one's will decisively. But looking at how we are able to avoid procrastination suggests that rationality is, at least on that domain, achieved rather differently.

Traditional time management advice has been mentalistic in assuming that solution will come from individuals thinking more rationally about how best to achieve their goals.

The focus is on cognitive accomplishments that are within the intentional control of the mind; they are, indeed, operations of the mind that are thought to flow directly into action. Much of the self-help literature also focuses on internal psychological factors, such as "fear of failure," that may discourage people from working as effectively as they might; for example, one popular book claims that "procrastination may be protecting a fragile sense of self-worth that is shaken by threats of judgment, control, closeness or distance. ${ }^{, 28}$ Rather than restructuring the temporal dynamics of choice, or changing their external incentives, individuals are encouraged simply to focus more clearly on the goals that they hope to attain, and the negative consequences of delay. ${ }^{29}$ Consider, for instance, the following list of "tips" for overcoming procrastination

Figure out what has the biggest payoff and do that first.

Be your own biggest fan.

Start sooner.

Stop busywork.

Set aside hopelessness and other forms of negative thinking.

Procrastination of Studying.

${ }_{29}$ Burk. Bura and Lenora M. Yuen, Procr. 
Procrastination and the Extended Will (Heath and Anderson).doc
Forgive previous mistakes and expect new ones ${ }^{30}$

While this author does eventually get around to making environmental recommendations, these typically occur last, after a lengthy set of purely psychological recommendations. There is no "offloading" here, nothing that reduces the motivational burden on the individual. These are all either direct psychological or else self-management strategies. As we have emphasized throughout, however - and as the empirical data suggest - avoiding procrastination is typically not a matter of these forms of cognizing. And this idea is beginning to be reflected in some approaches to time management. It is highly instructive, for example, to consider that the approach that has gained perhaps the most significantly following among knowledge workers and other professionals, found in David Allen's Getting Things Done, ${ }^{31}$ is resolutely "externalist" in its orientation. At the core of the system of personal organization and time management is the insistence that absolutely everything that it not immediately being worked upon be offloaded into an external physical system that one trusts, and pre-processed into "next action" chunks that are easily initiated, in response to contextual cues. Getting things done becomes then a decided non-mentalistic matter of turning amorphous responsibilities into a much less intimidating pile of "widgets to be cranked."

Even approaches to avoiding procrastination that understand the importance of material scaffolding still tend to focus rather individualistically on personal tools and habits. While these are important, we have seen how many of the supports that enable us to avoid procrastination are part of the social and built environment. This is clearest in the breach. As traditional offices, with their doors for shutting out distractions, have been replaced with open offices of cubicles, people have come to realize how much harder they have to work to keep on-task in the face of constant distractions. ${ }^{32}$ These and other changes in the "built" environment have changed in the past few decades, in a way that has forced individuals to rely ever more upon their "onboard" resources. Much the same can be said for the social environment, where freelancers and telecommuters find that working out of the home office leaves them without the supportive peer pressure of colleagues who will notice when they linger in the cafeteria or turn on a TV. What becomes clear is that, in such cases, "being selfdisciplined" is a contextualist property - not simply a personality trait but rather a feature of

\footnotetext{
${ }^{30}$ Lynn Lively, The Procrastinator's Guide to Success, 20-27.

David Allen, Getting Things Done: The Art of Stress-Free Productivity. For a fascinating analysis of the parallels between Allen's approach and empirical psychology, see Francis Heylighen and Clément Vidal,

${ }^{32}$ Steel, "The Nature of Procrastination," 82 .
}

Procrastination and the Extended Will (Heath and Anderson).doc persons as they are in particular contexts, with the requisite scaffolding. The further implication of this is that, although individual differences in personalities and skill sets clearly make a difference, some of the most important resources for overcoming procrastination are not portable, individual assets but shared goods - and goods that are being dismantled even as individual competition becomes more cutthroat.

A related but perhaps more controversial point can be made about the assumption of voluntarism, that is, the view that what is needed for avoiding forms of counterproductive behavior is a matter of our setting up systems, adopting practices, arranging our environment, and so on. The reality is that many of the most effective support structures - especially the social ones - are not built by us but built for us, part of an institutional and material heritage. And they are much more difficult to bring about intentionally than to dismantle. When a traditional institution such as the relatively early "last call" for drinks at British pubs is abolished, it is of course possible for people to institute, perhaps with friends, various strategies for avoiding procrastinating about getting to bed on time. But such arrangements are typically effortful and fragile, relative to taken-for-granted structures. To take just one example, consider the sleep-deprivation that has become a source of complaint in our society, which can plausibly be attributed, at least in part, to a tendency to procrastinate going to bed on time..$^{33}$ It used to be the case that TV stations would end their broadcasts at around midnight, bars and restaurants would close, subways and buses would stop running - the clear message being sent was: "time to go to bed." These institutional arrangements also made it much easier to go to bed on time, since there was little else to do after a certain hour. Now individuals must exercise more self-control about when to go to bed.

There is, we acknowledge, a danger of this point being seen as licensing paternalistic, authoritarian or traditionalist approaches. There are complex challenges here regarding how to balance a commitment to autonomy and freedom with the recognition that there are often real benefits of volitional supports being unchosen. And these complexities come into particularly sharp focus as one looks at the effects of their dismantling on those who have the fewest resources for handling the new individual responsibilities. This brings us to some concluding remarks about the political and public policy implications of this more externalis understanding of how to counter irrational human tendencies.

Concluding Remarks: Access to Scaffolding as an Issue of Public Policy

${ }^{33}$ On bedtime procrastination, see Ainslie, Breakdown of Will, p. 41. 
Procrastination and the Extended Will (Heath and Anderson).doc

Procrastination, like weakness of will, is a fascinating philosophical and

psychological puzzle. Equally fascinating, we have suggested, is our extraordinary ingenuity in recruiting our environment to solve our standard gaps in self-control.

It remains the case, however, that chronic procrastination has real and often devastating consequences. This is not just about last-minute Christmas shopping, or birthday cards getting sent late. By putting things off, people lose their jobs, their insurance, and their homes; their health suffers, and they tend to be "more miserable in the long term." ${ }^{34}$ What our externalist account of procrastination suggests is that this has potentially important political implications. For, to the extent to which we can assume (1) that certain social and economic developments in modern societies place increasingly high demands on the capacities comprising our ability to avoid procrastination, ${ }^{35}$ (2) that current trends toward individualization and liberalization involve the dismantling or abandonment of traditional forms of unchosen scaffolding, and (3) that the impact of the two preceding effects will be especially devastating for those who are already most vulnerable (think of the difficulties that the homeless have taking advantage of environmental supports) - then procrastination becomes, not just an issue of individual psychology, but also an issue of social justice. If people's life-chances are significantly shaped (perhaps along lines of class, race, degrees of disability, etc.) by their access to scaffolding, and if many forms of scaffolding are being dismantled or rendered inadequate as the result of social processes that could be addressed (to some extent, at least) by public policy, then the negative consequences of procrastination are not just the result of people failing to cognize appropriately as individuals; for these bad outcomes are partly the result of decisions and dynamics over which individuals have little control.

Does this mean that "society" should be responsible for people not paying their taxes on time, or putting off a visit to the doctor? Not quite. But to the extent that public policy decisions affect the availability of and access to the relevant scaffolding, and that these decisions can potentially affect individual life chances, a collective concern with individual welfare or the reduction of vulnerability or inequalities entails a concern for procrastination, along with an obligation to avoid dismantling the scaffolding that enables people, standardly, to keep procrastination in check. Once this concern is raised, of course, very controversia differences in social and political theory emerge regarding the best way to approach these
Procrastination and the Extended Will (Heath and Anderson).doc deficits and their distribution. Will an approach geared toward the development of new forms of social solidarity and ego-psychological developments be able to address these deficits? ? $^{36}$ Or do the arguments we have been making here point rather in the direction of a more paternalist, even if only "nudge paternalist" direction? ${ }^{37}$ These are complicated issues, but as a society, we should not put off addressing them.

\section{References}

Ainslie, George. Breakdown of Will. Cambridge: Cambridge University Press, 2001.

Allen, David. Getting Things Done: The Art of Stress-Free Productivity. New York: Penguin, 2001.

Anderson, Joel. “Autonomy Gaps as Social Pathology: Ideologiekritik without Paternalism" [in German translation] In Rainer Forst, Martin Saar, Rahel Jaeggi, und Martin Hartmann (eds.) Sozialphilosophie und Kritik.. Frankfurt: Suhrkamp, 2009.

Ariely, Dan. Predictably Irrational: The Hidden Forces That Shape Our Decisions. New York: HarperCollins, 2008.

Bargh, John A. and Tanya L. Chartrand. "The Unbearable Automaticity of Being." American Psychologist 54 (1999): 467-468.

Beck, Ulrich. Risk Society: Towards a New Modernity. London: Sage Publications, 1992.

Becker, Gary, and Kevin M. Murphy. "A Theory of Rational Addiction.” The Journal of Political Economy 96: (1988): 675-700.

Blunt, Allan K., and Timothy A. Pychyl. "Task Aversiveness and Procrastination: a MultiDimensional Approach to Task Aversiveness across Stages of Personal Projects." Personality and Individual Differences 28, no. 1 (January 2000): 153-167.

Burka, Jane B. and Lenora M. Yuen. Procrastination: Why You Do It, What To Do About It. Cambridge: De Capo, 1990.

Bruner, Jerome. Acts of Meaning: Four Lectures on Mind and Culture. Cambridge: Harvard University Press, 1992

Chirstensen-Szalanski, Jay. "Discount Functions and the Measurement of Patients' Values: Women's Decisions during Childbirth." Medical Decision Making 4 (1984): 47-58.

Clark, Andy. Being There: Putting Brain, Body, and World Together Again. Cambridge: MIT Press, 1997.

Dijksterhuis, Ap and John A. Bargh. "The Perceptual-Behavior Expressway: Automatic Effects of Social Perception and Social Behavior." In Advances in Experimental Social Psychology Vol. 30, edited by M. Zanna, 1-40. New York: Academic Press, 2001.

Gilhooly, Kenneth J. “Working Memory and Reasoning," in Jacqueline P. Leighton and

${ }^{36}$ Jürgen Habermas, "Individuation through Socialization: On George Herbert Mead's Theory of Subjectivity." Richard Thaler and Cass Sunstein, Nudge. See also, critically, Joel Anderson, "Autonomy Gaps as Socia Asert on Consent, Will, and Dignity." 
Procrastination and the Extended Will (Heath and Anderson).doc Robert J. Sternberg, The Nature of Reasoning (Cambridge: Cambridge University Press, 2004)

Gollwitzer, Peter M. and Veronika. Brandstätter. "Implementation intentions and effective goal pursuit." Journal of Personality and Social Psychology 73 (1997): 186-199.

Gollwitzer, Peter M. ARTICLE IN THIS VOLUME (to be added by the editors).

Habermas, Jürgen. "Individuation through Socialization: On George Herbert Mead's Theory of Subjectivity." In Postmetaphysical Thinking, 149-204.

Heath, Joseph. Following the Rules. New York: Oxford University Press, 2008.

Heylighen, Francis, and Clement Vidal. "Getting Things Done: The Science behind StressFree Productivity" Long Range Planning 41 (2008): 585-605.

Hume, David. Treatise of Human Nature. New York: Oxford University Press, 1978. Hutchins, Edwin. (1995a). Cognition in the Wild. Cambridge, Massachusetts: MIT press.

Kachgal, Mera M., L. Sunny Hansen, and Kevin J. Nutter. "Academic Procrastination Prevention/Intervention: Strategies and Recommendations". Journal of Developmental Education 25 (2001): 14-25.

Laibson, David. "Golden Eggs and Hyperbolic Discounting," Quarterly Journal of Economics, 112 (1997): 443-477

Lively, Lynn. The Procrastinator's Guide to Success. London: McGraw-Hill, 1999

Marcus, Gary. Kluge: The Haphazard Construction of the Human Mind. London: Faber and Faber, 2008

Mele, Alfred. Irrationality: An Essay on Akrasia, Self-Deception and Self-Control. New York: Oxford University Press, 1987.

Moon, Simon M., and Alfred J. Illingworth. "Exploring the Dynamic Nature of Procrastionation: A Latent Growth Curve Analysis of Academic Procrastionation," Personality and Individual Differences, 38 (2005): 297-309.

Muraven, Mark, \& Baumeister, Roy F. "Self-Regulation and Depletion of Limited Resources: Does Self-Control Resemble a Muscle?” Psychological Bulletin 126 (2000): $247-259$

Norman, Donald A. Things That Make Us Smart: Defending Human Attributes in the Age of the Machine. New York: Basic Books, 1993

Perry, John. "Structured Procrastination." http://www.structuredprocrastination.com (accessed September 7, 2008).

Pychyl, Timothy A., Richard W. Morin, and Brian R. Salmon. "Procrastination and the Planning Fallacy: An Examination of the Study Habits of University Students." Journal of Social Behavior and Personality 15 (2000): 135-152.

Ross, Don, David Spurrett, Harold Kincaid, and G. Lynn Stephens. Distributed Cognition and the Will. Cambridge, Mass: MIT Press, 2007.
Sjoberg, Lennart and Tommy Johnson. "Trying to Give Up Smoking: A Study of Volitional Breakdowns." Addictive Behaviors 3 (1978): 149-64.

Steel, Piers. "The Nature of Procrastination," Psychological Bulletin, 133 (2007): 65-94.

Thaler, Richard H.. "Mental Accounting and Consumer Choice." Marketing Science 4 (1985): 199-214.

Thaler, Richard H.. "Saving, fungibility and mental accounts." Journal of Economic Perspectives, 4 (1990): 193-205.

Thaler, Richard, and Cass Sunstein. Nudge: improving decisions about health, wealth, and happiness. New Haven: Yale University Press, 2008.

Trope, Yaacov and Nira Libennan, "Temporal Construal and Time-Dependent Changes in Preference," Journal of Personality and Social Psychology 79 (2000): 876-889

Tullier, L. Michelle. "The Procrastination Epidemic," In The Complete Idiot's Guide to Overcoming Procrastination, 17-26. New York: Alpha Books, 1999.

Van Eerde, Wendelien. "Procrastination: Self-regulation in Initiating Aversive Goals," Applied Psychology An International Review 49:3 (2000): 372-389.

Vygotsky, Lev S. Thought and Language, rev. ed. Cambridge: The MIT Press, 1986.

Wertsch, James V. Mind As Action. New York: Oxford University Press, 1998

White, Mark D. "Behavioral Law and Economics: The Assault on Consent, Will, and Dignity." In Gerald Gaus, Christi Favor, and Julian Lamont (eds.), New Essays on Philosophy, Politics \& Economics: Integration and Common Research Projects, Stanford: Stanford University Press, forthcoming.

Wieber, Frank. ARTICLE IN THIS VOLUME - (to be added by the editors).

Ziesat, Harold A. Jr., Ted L. Rosenthal and Glenn M. White. "Behavioral self-control in treating procrastination of studying." Psychological Reports 42 (1978): 59-69. 